\title{
Accuracy of Triple Test Score in The Diagnosis of Palpable Breast Lump
}

\author{
Ghimire B, ${ }^{1}$ Khan MI, ${ }^{1}$ Bibhusal T, ${ }^{1}$ Singh $Y,{ }^{1}$ Sayami $P^{1}$ \\ 'Department of Surgery, Institute of Medicine Tribhuvan University Teaching Hospital, Kathmandu, Nepal
}

\begin{abstract}
Breast lump is a very sensitive issue for the patient so a reliable, non invasive and prompt diagnosis helps to lessen the associated anxiety and leads to early definitive treatment. The aim of this study was to evaluate the acuracy of Triple Test Score (TTS) as a clinical tool for the diagnosis of a palpable breast lump. This diagnostic test study was carried out in the Department of Surgery of Tribhuvan University Teaching Hospital. Of the 117 patients admitted with breast diseases from the breast clinic over thirteen months, 87 had breast lump. Fifty patients underwent Triple Test Score ( physical examination, mammography and fine needle aspiration cytology) and were categorized into benign, suspicious and malignant. This was later correlated with the histopathological findings. Nineteen patients with breast lumps interpreted by TTS as benign correlated with the histopathological findings whereas of 31 malignant lumps, 30 turned out to be malignant and one benign. This gives TTS an over all accuracy of $98 \%$ with $100 \%$ sensitivity, $95.2 \%$ specificity and positive predictive value of $96.7 \%$. Carcinoma was seen in $29(58 \%)$ cases in the age group of 35 to 70 years. The mean age at diagnosis of benign and malignant disease was 41.8 and 45.1 years respectively. In conclusion, TTS is an accurate and least invasive diagnostic test based on which definitive treatment can be initiated.
\end{abstract}

Key words : breast lump, carcinoma breast, triple test score

\section{INTRODUCTION}

One-fourth of women suffer from breast disease in their life time. ${ }^{1,2}$ Carcinoma of breast is the second most common cancer in the world. ${ }^{3}$ With the improvement in health care and increasing longitivity, more and more females are being exposed to the risk of developing breast carcinoma. In the European Union, the incidence of breast cancer is 110 in one million with more than onethird of them succuming to it, however, there is marked geographical variation. ${ }^{4}$ The lifetime risk of developing breast cancer is 1 in $8 .{ }^{5}$ In developing countries, incidence of breast cancer ranges from 18 to 19 per million leading to death of 5 to 10 per million. ${ }^{6}$
Lump in the breast has been viewed with scepticism resulting in delay in seeking treatment. Timely and accurate diagnosis of a breast lump with early intervention can be lifesaving. There are various modalities for the diagnosis of a breast lump such as mammography, ultrasonography, fine needle aspiration cytology but none of them are without impunity. Delay can lead to deprivement of curative treatment where as aggressive management can expose the patient to unwarrented surgeries and hence psychological and social traumas to the patient and the risk of litigtion to the surgeon.

\footnotetext{
Correspondence:

Dr. Ghimire Bikal

P.O.Box : 8975 EPC 524, Kathmandu, Nepal

Phone no : $+977-9851095679$

E_mail: bikalghimire@gmail.com
} 
Ghimire et al. Triple test score for breast lump

A simple, non invasive but reliable test can make a huge difference in the management. In this context "triple assessment" and the "Triple test Score" (TTS) is a simple and affordable diagnostic modality of a breast lump. In this study, we evaluated the efficacy of TSS in correctly predicting the nature of a breast lump by comparing it with the histopathological diagnosis so that we can safely subject our patients to management based on it.

\section{MATERIAL AND METHODS}

The study was conducted for 13 months on patients with palpable breast lump presenting to Tribhuvan University Teaching Hospital and subsequently undergoing surgery. Approval for the study was taken from the 'Institutional Review Board' and informed consent was taken from the patients. Patients declining to undergo fine needle aspiration cytology (FNAC) or surgery or those with breast abscess, antibioma, mastitis, infected cyst, mammary fistula were excluded from the study

Women aged 35years or older with palpable breast lump underwent prospective assessment by simultaneous physical examination, mammography and FNAC.

All patients had a TSS assigned to them. Each component was designated as benign, suspicious and malignant and rated as 1,2 and 3 respectively. TSS is the sum of these scores with a minimum score of 3 (3-4; concordant benign) and a maximum score of 9 (6-7; concordant malignant), 5 having intermediate risk needing further evaluation before any definitive treatment. All the patients underwent surgery according to the disease indicated by the score. The score was later compared with the histopathological report obtained after the surgery. Statistical analysis was done with SPSS version 10.0 was used and diagnosis and demography was comparied using variance and chi-square test .

\section{RESULT}

Total 117 patients were admitted with breast diseases from the breast clinic and 87 of them had breast lump but only 50 fullfilled the inclusion criteria. Breast carcinoma was seen in $40 \%$ of patients in 3rd decade and $100 \%$ in 6 th decade.

Malignancy was seen in $29(58 \%)$ cases in the age group of 35 to 70 years. The mean age at diagnosis of benign and malignant disease was 41.8 and 45.1 years respectively. The observed freequency of lump being diagnosed as malignant was one in four in the 4th decade and two in five in the 5 th decade.

After the age of 50 , the chances of diagnosis of a benign lump was less than $21.42 \%$ and it further decreased with age (Figure 1).

Of the 50 breast masses, clinically, 20 (40\%) were benign; 29 (58\%) were malignant and 1 (2\%) was found to be suspicious for malignancy and by mammography, 21 (42\%) were benign, 27 (54\%) were malignant and $2(4 \%)$ were found to be suspicious for malignancy (Table 1). FNAC revealed $20(40 \%)$ to be benign, 29 $(58 \%)$ to be malignant and one $(2 \%)$ was found to be suspicious for malignancy.

Histopathology confirmed 21 cases (42\%) to be benign and 29 cases $(58 \%)$ to be malignant. One case with TTS of 6 and interpreted as malignancy (ie: suspicious of malignancy by all three tests) was found to be histologically benign.

TTS of 49 (98\%) patients correlated with histopathology except for one patient (Table 1 ).

\section{$\square$ Malignant $\square$ Benign}

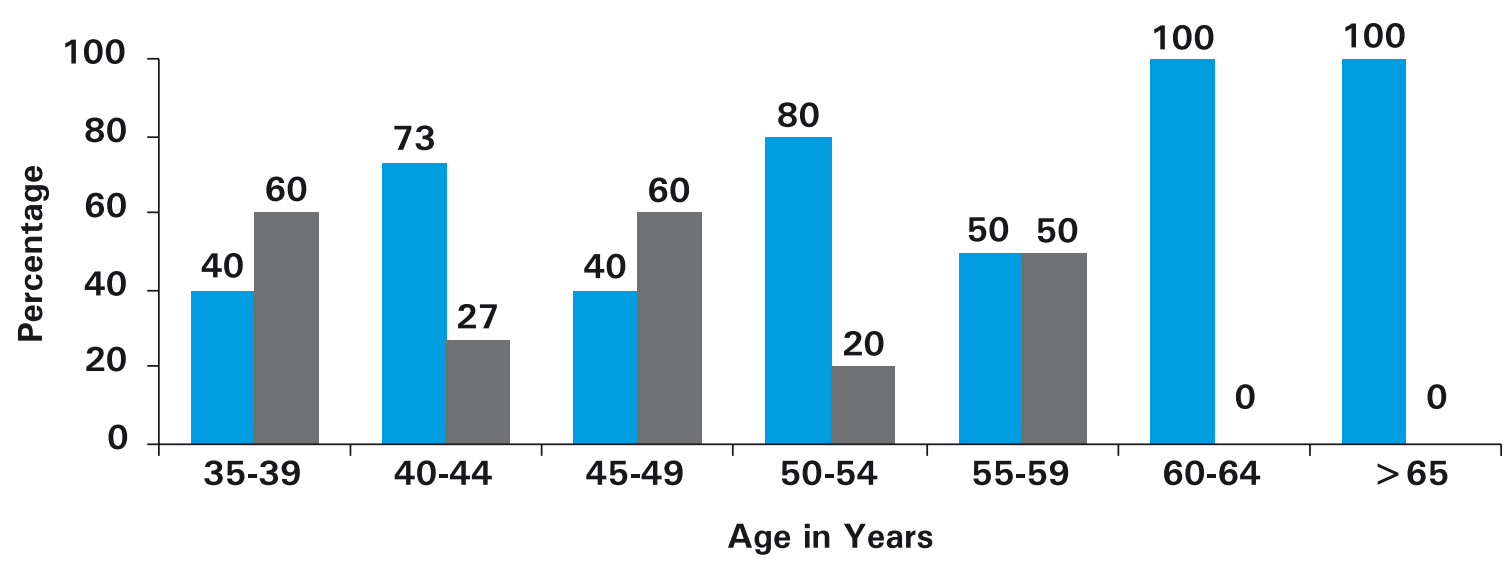

Figure 1. Frequency of malignant and benign diseases in different age groups 
Ghimire et al. Triple test score for breast lump

Table 1. Correlation of all the components of T T Score and the histopathology

\begin{tabular}{|c|c|c|c|c|}
\hline Clinical * & Mammogram & FNAC & TT Score & Histopathology \\
\hline $\begin{array}{l}\text { Benign } \\
(n=20)\end{array}$ & Benign & Benign & $\begin{array}{l}\text { Benign } \\
(\leq 4)\end{array}$ & $\begin{array}{l}\text { Benign } \\
20(40 \%)\end{array}$ \\
\hline $\begin{array}{l}\text { Suspicious } \\
(n=1)\end{array}$ & Suspicious & Suspicious & Malignancy $(\geq 6)$ & $\begin{array}{l}\text { Benign } \\
1(2 \%)\end{array}$ \\
\hline \multirow[t]{3}{*}{$\begin{array}{l}\text { Malignancy } \\
\text { (n-29) }\end{array}$} & Benign & Malignancy & Malignancy & $\begin{array}{l}\text { Malignant } \\
1(2 \%)\end{array}$ \\
\hline & Malignancy & Malignancy & Malignancy & $\begin{array}{l}\text { Malignant } \\
27(54 \%)\end{array}$ \\
\hline & Suspicious & Malignancy & Malignancy & $\begin{array}{l}\text { Malignant } \\
1(2 \%)\end{array}$ \\
\hline
\end{tabular}

* Number of cases accessed clinically

TTS had a sensitivity of $100 \%$ with specificity of $95.2 \%$ and Positive predictive value of $96.7 \%$ (confidence interval of $95 \%$ ). It had an accuracy of $98 \%$. with false positive rate of $3.3 \%$.

Amongst them, 24 (48\%) had breast lump in the upper outer quadrant. Fibroadenoma (85\%) was the most common clinical diagnosis of the benign lumps where as Infiltrating ductal carcinoma was seen in $98 \%$ of all malignant lesion.

\section{DISCUSSION}

In our series, prospective analysis of TTS on 50 patients and confirmating the results with the histopathological finding showed it to be highly sensitive and specific. Its accuracy was more for malignant lesions hence, TTS can be used for providing definitive therapy specially in our context where 'Frozen section' is not routinely avilable.

In our study, peak incidence of carcinoma was seen in the 4th and 5th decade. After the age of 50 years, the chance of diagnosis of a benign lump is less than $50 \%$ and it further decreases with age. The mean age of diagnosis of a benign lump was 40.8 years and malignant was 45.7 years. This was considerably less than that seen in the western population (57 years) and slightly less than that observed in our population a decade earlier (47 years). ${ }^{7,9}$ In Malaysia, the age standardised incidence rate of breast cancer for 2004 was 46.2 per 100,000 with the commonest age of presentation being between 40-49 years. This might imply malignancy to be common at an early age group in our subcontinent warranting more caution in the management of breast lump in the middle age group. In this series, the commonest presenting symptom was a breast lump (90\%) noticed by the patient herself and on average, a women waited for three months before seeking medical attention. ${ }^{8}$

The incidence of malignant lumps in the sixth decade was $52 \%$ which is higher than that seen in the western population (44\%). This reflects the unawareness of the elderly females to the significance of a breast lump and the tendency to neglect asymptomatic lumps presenting to the surgeon more with a symptomatic malignant lump. Amongst these 50 patients, Infiltrating ductal carcinoma $(57 \%)$ was the most common diagnosis followed by Fibroadenoma (34\%). Of all the cases, 96.7 $\%$ correlated with the interpretation of TTS and sixty percent was predicted to be malignant. One patient with a breast lump suspicious to be malignant by TTS (Clinically and mammographically benign and FNAC as malignant) later came out to be malignant where as none of the benign cases turned up to be malignant on histopathology. In the detection of breast cancer, falsenegative rate of mammography has been consistently reported to be approximately $10 \%$, as determined by studies such as the Breast Cancer Detection Demonstration Project. ${ }^{10}$ So, a negative mamography cannot exclude malignancy in women with a palpable mass. FNAC on the otherhand has diagnostic sensitivity of $97.7 \%$ and specificity of $99.4 \%$ with false positive and negative value of 0.6 and 2.28 respectively. ${ }^{11}$ Clinical examination of the breast has been shown to identify 5 percent of breast cancer, with pooled data estimating $54 \%$ sensitivity and $94 \%$ specificity. ${ }^{12}$ There is wide variation in the technique of clinical breast examination resulting in variable sensitivity $129 \%$ variance) and specificity (33\% variance). ${ }^{13}$ In one study in a community, only $4 \%$ of women with an abnormal clinical breast examination had cancer. ${ }^{14}$ Thus relying solely on clinical breast examination may not help in the management. A Cochrane review concluded that selfbreast examination has no beneficial effect and actually 
Ghimire et al. Triple test score for breast lump

increases the number of biopsies performed prompting them to recommend that women not perform selfbreast examination. ${ }^{15}$ Even the U.S. Preventive services task force (USPSTF) found insufficient evidence to recommend breast self-examination. ${ }^{16}$ These findings prompt us to review strategies for social awareness and education program in our socioeconomic context.

Though the sample size is small, with this result, we can safely implement TTS on patients with breast lump without risking the safety of the patient. Patients with benign lesion on TTS can be kept on followup where as suspicious lesions can be subjected to biopsies or wide excisions.

\section{CONCLUSION}

Triple test score can safely be used as an acurate and least invasive diagnostic test and based on its interpretation, definitive treatment can be initiated which would reduce the need for unnecessary biopsies. The strength of TTS seems to lie in its ability to reliably predict benign lumps and thus avoid major surgeries. Given the increased incidence of malignant lumps in elderly females and the tendency to hide asymptomatic lumps, we need more awareness programs targeting this age group.

\section{REFERENCES}

1. Siddiqi K, Imtiaz RM. Pattern of breast diseases: preliminary report of breast clinic. J Coll Physician Surg Pak 2001;11:497500 .

2. Ghumro AA, Khaskjeli NM, Memon AA, et al; Clinical profile of patients with breast cancer. J Coll Physician Surg Pak 2002;12:28-31.

3. Pestalozzi BC, luporsi GE, Jost LM, et al; ESMO Minimum Clinical Recommendations for diagnosis, adjuvant treatment and follow-up of primary breast cancer, Ann Onc 2005 May;16:i7-i9.

4. Stewart BW. and Kleihues P. (Eds):World Cancer Report. IARC Press. Lyon 2003;188-193.

5. American Cancer Society. Breast Cancer Facts \& Figures. 2005-2006. Atlanta: American Cancer Society, Inc.

6. Ferlay J, Bray F, Pisani P and Parkin DM. GLOBOCAN 2002. Cancer incidence, mortality and prevalence worldwide. IARC Cancer base. IARC Press, Lyon, 2004;5(2.0).

7. Singh $\mathrm{Y}$, Sayami $\mathrm{P}$, Nakagawa $\mathrm{H}$, et al; Nepalese breast cancer in relation to reproductive factors: Comparision between Nepalese and Japanese cases. Anticancer Research 2002;22:319-324.

8. Yip CH, Taib NA, Mohamed I. Epidemiology of breast cancer in Malaysia: Asian pac J Cancer Prev 2006 July;7(3):369-374.

9. Yusuf A, Khan JS, Bhopal Fg, et al; Level of awareness about breast cancer among females presenting to a general hospital in Pakistan. J Coll Physician Surg Pak 2001;11:131-135.
10. Mary SS, Eric LR, Baker JA. Negative predictive value of sonography with mammography in patients with palpable breast lesions. AJR 2001;177:1167-1170.

11. Qingqing $H$, Xihong F, Tinggui $Y$, Eleven years of experience reveals that fine-needle aspiration cytology is still a useful method for preoperative diagnosis of breast carcinoma. The Breast 2007 June;16(3):303-306.

12. McDonald S, Saslow D, Alcciati MH. Performance and reporting of clinical breast examination; a review of the literature. CA Cancer J Clin 2004;54:345-361.

13. Fletcher SW, Malley MS, Pilgrim CA, Gonzalez JJ. How do women compare with internal medicine residents in breast lump detection? A study with silicone models. J Gen Intern Med 1989;4:277-283.

14. Bobo LK, Lee NC, Thames SF. Findings from 752,081 clinical breast examinations reported to a national screening program from 1995-1998. J Natl Cancer Inst 2000:92:971-976.

15. Kosters JP, Gotzsche PC. Regular self examination or clinical examination for early detection of breast cancer. Cochrane Database syst Rev 2003; (2):CD003373.

16. Screening for Breast Cancer, Topic Page. November 2003. U.S. Preventive Services Task Force. Agency for Healthcare Research and Quality, Rockville, MD. [Release Date: February 2002] Avilable from: URL:http://www.ahrq.gov/clinic/ uspstf/uspsbrca.htm 